\title{
Integrating fossil and extant lineages: an examination of morphological space through time (Araneae: Archaeidae)
}

\author{
Hannah M. Wood: Department of Entomology, National Museum of Natural History, Smithsonian Institution, PO Box \\ 37012, MRC105, Washington, DC 20013-7012, USA. E-mail: woodh@si.edu
}

\begin{abstract}
The integration of fossil and extant lineages in evolutionary analyses allows for morphological change to be examined over long periods of time. This study explores how fossil archaeid species compare with extant species in terms of morphological diversity. By adding additional data for fossil species, this study builds upon the total evidence phylogenetic data matrix and the carapace/chelicerae measurements of an earlier analysis. Phylogenetic analyses recovered a monophyletic Archaeidae crown-group, and there is some support for a monophyletic fossil clade. However, analyses did not recover a monophyletic Archaeidae: the fossil Lacunauchenius Wunderlich, 2008 fell outside of the remaining archaeids, although its placement was only weakly supported. Fossil archaeids are morphologically diverse, and compared to extant species, occupy a novel morphological space characterized by shorter features. There has been a shift through time towards the more elongated features of the extant species. Given the unique morphologies of the fossil species, it is likely that fossil archaeids occupied unique niches that are no longer occupied by extant species.
\end{abstract}

Keywords: Morphology, evolution, phylogenetics, Palpimanoidea, arachnid

The fossil record offers the possibility to examine morphological change over long periods of time, and the integration of fossil and extant lineages in phylogenetic analysis is crucial for examining trait evolution (Slater et al. 2012). The fossil record suggests that palpimanoid spiders were possibly more diverse and more widespread in the past, having several lineages known only from fossils (Petrunkevitch 1942; Eskov \& Wunderlich 1995; Selden et al. 2008; Wunderlich 2008). Archaeidae, in particular, is a palpimanoid family that has an unusual distribution and a well-documented fossil record: fossil archaeids are known from only the Northern Hemisphere, while extant lineages occur only in the Southern Hemisphere, restricted to Madagascar, Australia, and South Africa (Forster \& Platnick 1984). A divergence dating study that included fossil and extant taxa concluded that the split between the extinct northern and extant southern faunas likely relates to Pangaea breaking into Gondwana and Laurasia in the Jurassic (Wood et al. 2013). So, it appears that archaeids were once more widespread, but are now restricted to relictual areas. However, within their present day distributions the extant clades have diversified, with the timing of diversification in Australia congruent with Miocene aridification (Rix \& Harvey 2012b), and in South Africa possibly congruent with Miocene uplift of the Great Escarpment (Wood et al. 2015). Diversification in the Madagascan clade may be due to geoclimatic events that are more ancient than the Miocene, with repeated climatic events leading to the build-up of sympatric species in montane, rainforest areas (Wood et al. 2015).

Archaeid spiders are morphologically bizarre: these spiders have an extremely modified carapace that is extended and tubular in structure, that encircles the cheliceral bases, and gives archaeids the appearance of a "neck" and "head" (Fig. 1). This unusuai morphology directly relates to their predatory behaviors: the modified carapace allows for highly maneuverable chelicerae that are used to attack their spider prey at a distance (Forster \& Platnick 1984; Wood et al. 2012). There is a diversity of "neck" shapes among archaeids, with "necks" of varying degrees of elongation, from long and constricted to short and stout, with different morphs independently evolving within the family (Wood et al. 2007). The morphological diversity in the carapace and chelicerae shape in the extant clades seems to directly relate to the diversification patterns mentioned above: the Madagascan clades show an increased rate of morphological trait evolution compared to the Australian and South African clades (Wood et al. 2015). It may be that trait divergence is increased in the Madagascan clades due to species living in sympatry, as has been found in Percina darters (Carlson et al. 2009).

While previous studies in archaeids incorporated fossils in order to date divergence events and to understand phylogenetic relationships, the fossils were not incorporated into the studies of trait evolution and morphological diversity. Here, I specifically focus on the fossil archaeid species (Table 1), which come from Bitterfield amber (age disputed, from Eocene to Miocene), Baltic amber (Eocene age), and Burmese amber (Cretaceous age), as well as compression fossils from InnerMongolia (Jurassic age). Using the total evidence dataset from Wood et al. (2015), which is the most comprehensive archaeid phylogenetic study to date, I add several fossil taxa to the matrix, scoring them for morphological characters, and I also take morphological measurements for the fossil lineages. The motivation for this study is to explore how the morphological space in archaeid spiders has changed over time.

\section{METHODS}

Phylogenetic analysis and divergence dating.- - In order to examine the evolutionary history of living and extinct archaeids, a phylogenetic analysis and a divergence dating analysis were executed using the total evidence data matrix modified from Wood et al. (2015). This data matrix contains living and fossil archaeids, with the living taxa scored for both molecular and morphological characters and the fossil taxa scored only for morphological characters. The four known extant genera from Madagascar, Australia and South Africa, are represented in this matrix: Eriauchenius Cambridge, 1881, 
Austrarchaea Forster \& Platnick, 1984, Afrarchaea Forster \& Platnick, 1984 and Zephyrarchaea Rix \& Harvey, 2012a, as well as the monophyletic "Gracilicollis Group" (Wood 2008) that is currently considered part of Eriauchenius. Five fossil genera (out of 11 fossil genera in total) were represented in this matrix: Archaea Koch \& Berendt, 1854, Burmesarchaea Wunderlich, 2008, Baltarchaea Eskov, 1992, Myrmecarchaea Wunderlich, 2004, and Patarchaea Selden, Huang \& Ren, 2008. For the current study, two additional genera represented by three additional fossil species were added to the matrix: Lacunauchenius speciosus Wunderlich, 2008, Saxonarchaea dentata Wunderlich, 2004, and Saxonarchaea diabolica Wunderlich, 2004 (see Table 1 for a list of the fossil specimens used in this study). Archaeids belong to the Palpimanoidea (Wood et al. 2012): the outgroup taxa included 13 terminals representing the remaining four Palpimanoidea families plus one species in the family Austrochilidae, and the resulting tree was rooted with one species of Haplogynae (family Segestriidae). The new matrix, with the inclusion of 3 fossil taxa and with duplicate taxa pruned, had a total of 77 terminals. The final concatenated matrix had 5584 characters, consisting of: 111 morphological characters (reduced from the original 126 when phylogenetically uninformative characters were excluded); 658 base pairs (bp) for the mitochondrial protein-coding gene Cytochrome c Oxidase subunit 1 (COI); 328 bp for the nuclear protein-coding gene Histone-H3 (H3); and 2572 bp and $1915 \mathrm{bp}$, respectively, for the ribosomal nuclear genes $18 \mathrm{~S}$ and $28 \mathrm{~S}$.

The morphology-only portion of the data set was analyzed under parsimony using TNT version 1.5 (Goloboff et al. 2008): characters were treated as unweighted and non-additive ("unordered"), and gaps were treated as missing (command 'nstates nogaps'). Uninformative characters were inactivated (command 'xinact'). Optimal trees were searched using random addition sequences to generate Wagner trees, followed by the tree-bisection reconnection (TBR) algorithm, making 1000 replications and saving up to 10 trees per replication (command 'mult $=$ tbr replic 1000 hold 10 '). To examine clade support values, jackknife calculations were performed on group frequencies with the probability of elimination set to $P$ $=0.36$, consisting of 1000 pseudoreplicates of 10 random addition sequences, followed by 10 iterations of TBR and retaining 10 trees per replicate (command: 'mult: no ratchet replic 10 tbr hold 10; resample jak replic 1000;').

To examine the timing of divergence, a time-calibrated phylogeny was created using Bayesian methods by treating archaeid fossil taxa as non-contemporaneous tips following the methods of Pyron (2011) and Wood et al. (2013). This analysis was performed using the combined molecular and morphological dataset. For each terminal fossil, the geological stage and reference are listed in Table 1. The fossil tip date was treated as a uniform distribution spanning the entire estimated age range of the fossil species. There is dispute around the age of the Bitterfeld amber deposits (Dunlop 2010), with age estimations ranging from the Eocene to the Oligocene. Because of this, the tip date for the two species of Saxonarchaea Wunderlich, 2004 was broad, being set to 23$49 \mathrm{Ma}$. The root age was constrained, being treated as a normal distribution with a mean of $225 \mathrm{Ma}$ with soft upper and lower bounds (standard deviation $=30 ; 5-95 \%$ bounds $=$

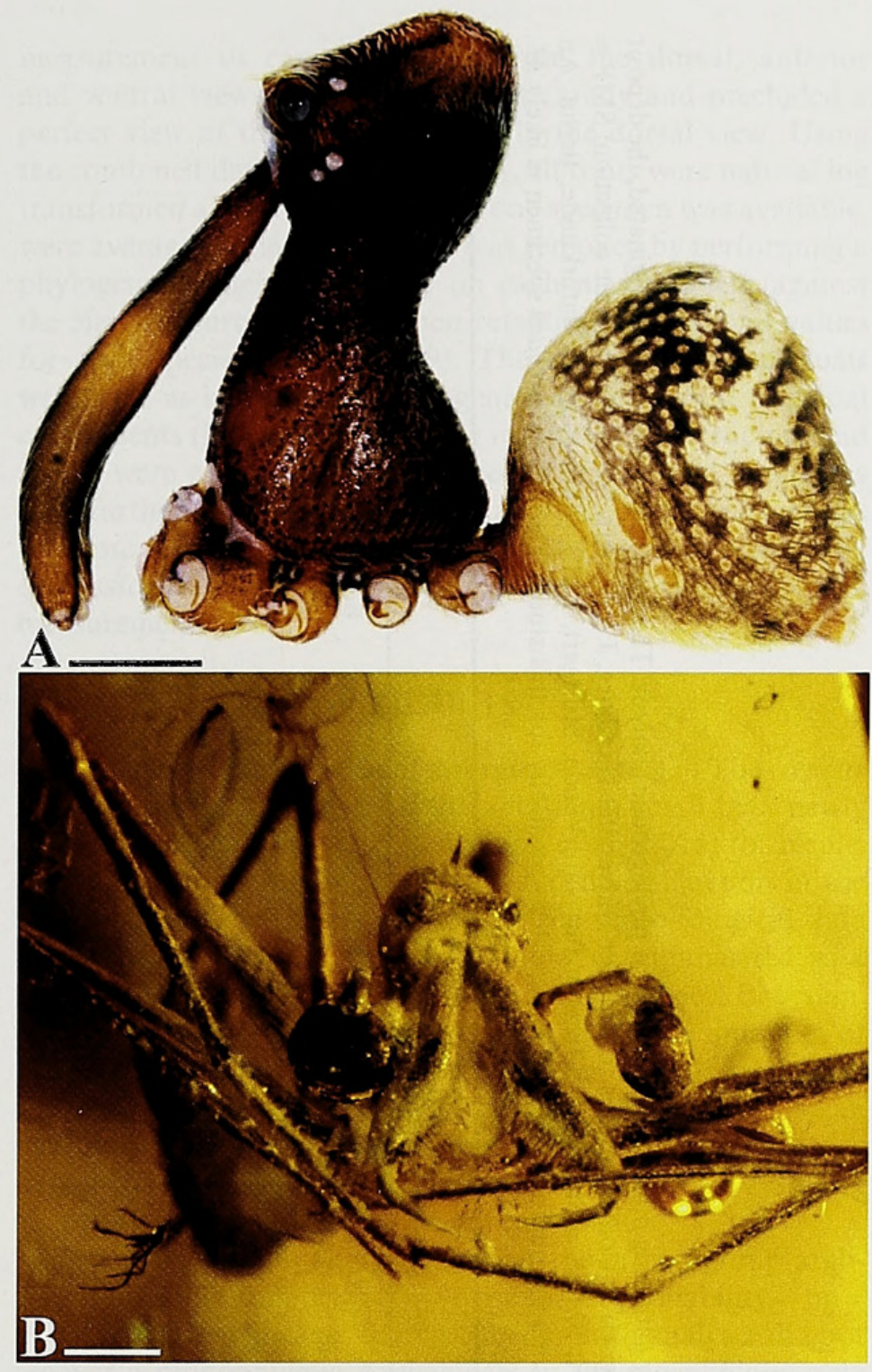

Figure 1.-Archaeid spiders: A. Eriauchenius sp., male, lateral view, legs removed. B. Archaea paradoxa, male, from Baltic amber, Eocene age, anterior view. Scale bars $=0.5 \mathrm{~mm}$.

175.7-274.3 Ma), based on the age of the oldest Araneomorphae fossil (Selden et al. 1999). The breadth of this prior constraint was intentionally large to contain the true age of Araneomorphae divergence and so as not to bias the study. The mean node ages and their $95 \%$ Bayesian credible interval (CI) were estimated using a relaxed clock model implemented in BEAST version 1.8.2 (Drummond et al. 2012). The data partitions and nuclear substitution models were the same as the Wood et al. (2015) divergence dating analysis: partition $1=$ morphology, set to a standard discrete Markov model (Lewis 2001); partition $2=$ COI codon position 3, set to a HasegawaKishino-Yano (HKY) model; partition $3=$ COI codon positions 1 and 2 and $\mathrm{H} 3$, set to a HKY model; and partition $4=18 \mathrm{~S}$ and $28 \mathrm{~S}$, set to a $\mathrm{K} 80+\mathrm{I}+\mathrm{G}$ model. The molecular clock model was set to relaxed, uncorrelated lognormal and the tree prior was set to speciation, birth-death process. Two MCMC analyses were run for 50 million generations, sampling the chain every 1000 generations. Log files were visualized in Tracer version 1.4 (Rambaut et al. 2014) to ensure that the effective sample size of the combined log files 


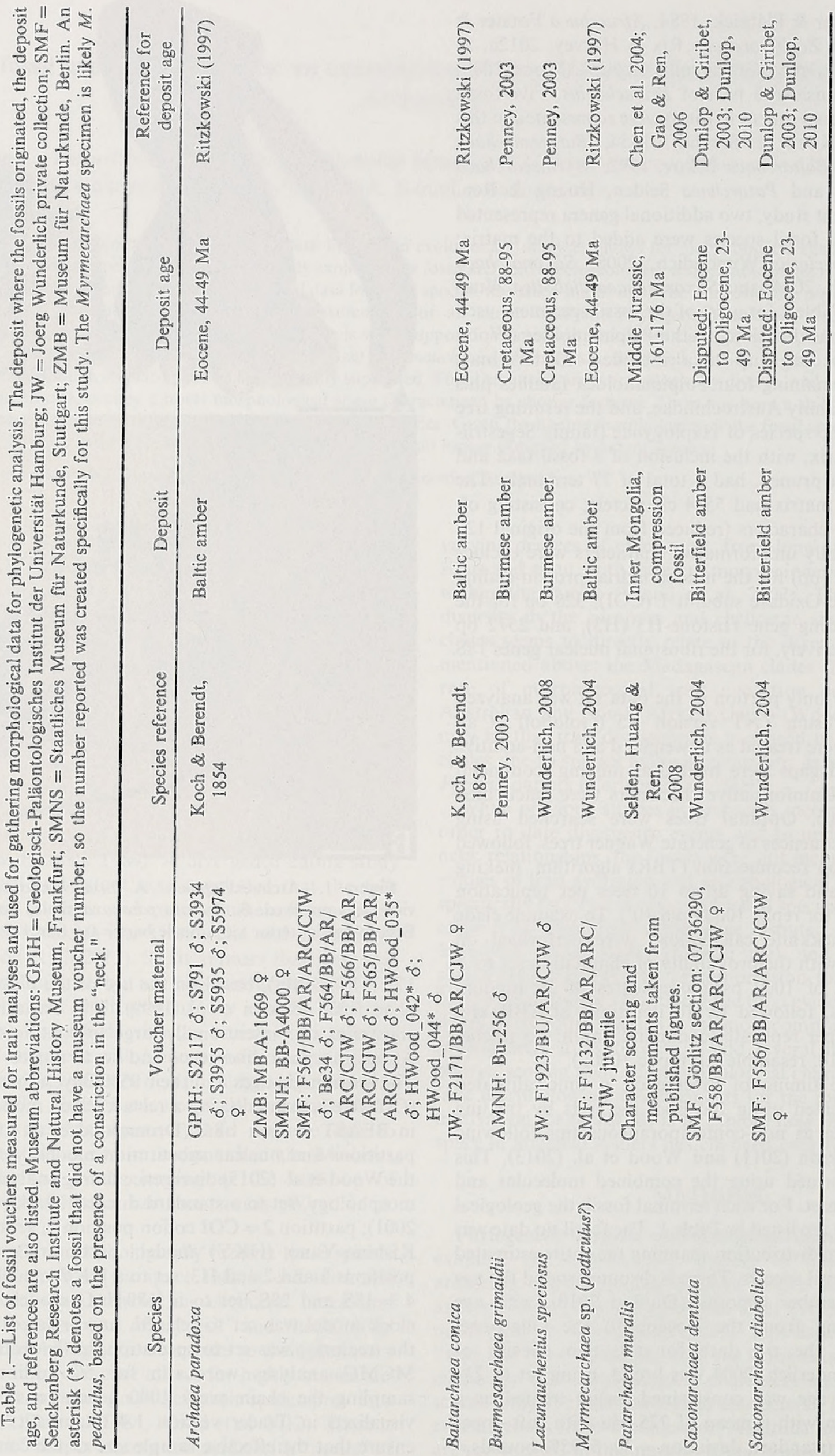




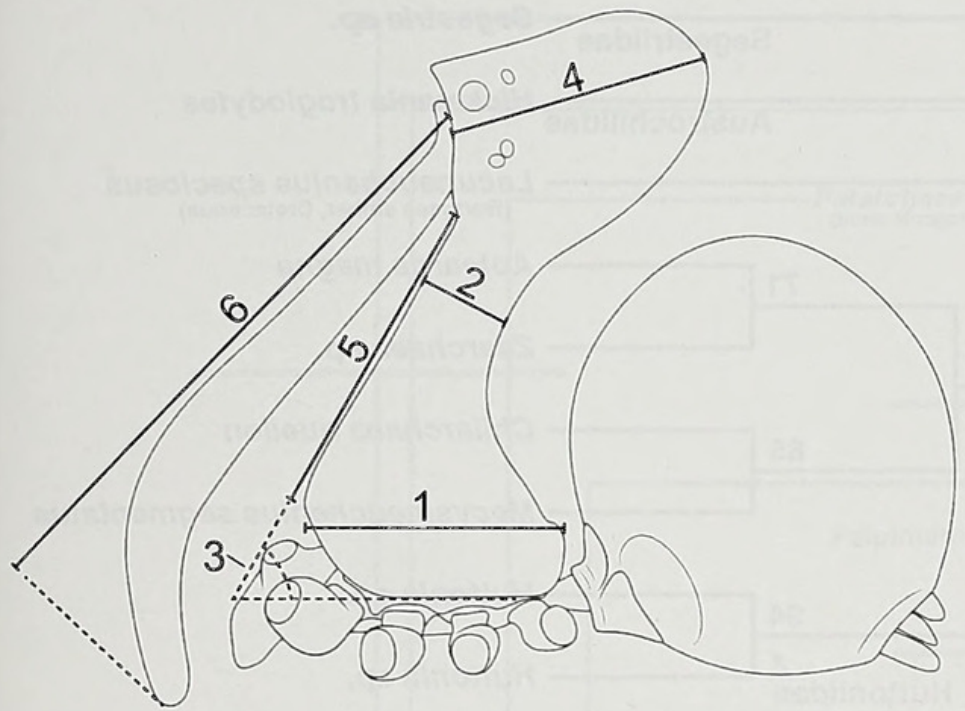

Figure 2.-Diagram showing the measured morphological traits (reproduced from Wood et al. 2015): 1, carapace length; 2, carapace constriction; 3, carapace angle; 4, "head" length; 5, "neck" length; 6 , chelicerae length. Measurement 7 (femur I length) not shown.

reached 200 for all parameters (Drummond et al. 2006). The burn-in $(20 \%)$ was removed from each independent run and the resulting tree files were combined.

Measurement data and morphological evolution.-Wood et al. (2015) measured seven traits of the cephalothorax and one measurement of standard length per species for 51 extant species (Fig. 2). The same measurements were made for the eight fossil taxa included in the phylogeny and were added to the Wood et al. (2015) data matrix (see supplemental information for the measurements of all taxa: online at http://dx.doi.org/10.1636/JoA-S-16-039.s1). The measurements were as follows: (1) carapace length; (2) carapace constriction, defined as the depth from anterior to posterior of the narrowest portion of the "neck" in the lateral habitus view; (3) carapace angle, defined as the angle between the posterior edge of the lateral side of the carapace (the portion above coxae II and III) and the anterior edge of the "neck" in the lateral view; (4) anterior "head" length, defined as the length between the clypeus and the posterior edge of the "head," taken perpendicular to the cheliceral foramen in the dorsal view; (5) "neck" length, defined as the length from the bottom edge of the cheliceral foramen to the bottom edge of the carapace, taken in the anterior view; (6) chelicerae length; and (7) length of femur I. Carapace width was used as the measurement for size. These traits were selected because of their ecological and functional significance in predatory attacks (Wood 2008; Wood et al. 2012). Measurements for Archaea paradoxa C. L. Koch \& Berendt, 1854 and Patarchaea muralis Selden, Huang \& Ren, 2008 were taken from 16 and 3 specimens, respectively, and were averaged, and the remaining fossil species measurements, due to specimen availability, were taken from only one specimen (Table 1), with the following exceptions: (1) P. muralis was not physically examined and measurements were taken from published images; (2) the carapace width measurement for Saxonarchaea dentata was taken from a value reported in the literature (Wunderlich 2004), as the amber shape prevented a dorsal view of the carapace; and (3) the carapace width measurement for Lacunauchenius speciosus was based on an average measurement of carapace width from the dorsal, anterior and ventral views, as the amber was cloudy and precluded a perfect view of the carapace width in the dorsal view. Using the combined data set for all species, all traits were natural log transformed and, when more than one specimen was available, were averaged. The effect of size was removed by performing a phylogenetic linear regression on each measurement against the size measurement, and then retaining the residual values for each species (Revell 2009). The size-corrected residuals were used as inputs for a phylogenetically corrected principal components (PC) analysis and the resulting eigenstructure and scores were extracted for each species. Two fossil specimens were further removed from the PC analysis, as Lacunauchenius speciosus is likely not an archaeid (see phylogenetic results and discussion), and Patarchaea muralis was missing some measurements.

\section{RESULTS}

Phylogenetic analysis and divergence dating.- The results reported here deal only with the additional fossil taxa newly added for the current study; see Wood et al. (2015) for results and a discussion of trait evolution and diversification in the extant clades. Parsimony analysis of the morphological data recovered 940 trees of 190 steps that were summarized as a strict consensus tree (Fig. 3). For the total evidence, Bayesian, divergence dating analysis, there were moderate amounts of rate heterogeneity, meaning that the data are not clock-like: the mean coefficient of variation was 1.051 and the mean ucld.stdev was 0.859 . There was not strong evidence for autocorrelation (mean covariance $=0.152$ ). The resulting summary chronogram is presented in Fig. 4.

Both phylogenetic analyses recover the crown-group archaeids (jackknife support $=\mathrm{jk}=96$; posterior probability $=\mathrm{pp}=$ 0.78 ), with fossil lineages falling outside. Both analyses did not recover a monophyletic Archaeidae: in the morphology-only analysis the fossil Lacunauchenius Wunderlich, 2008 fell outside of the remaining archaeids, although its placement was not supported; in the total evidence analysis the fossils Lacunauchenius and Patarchaea fell outside the remaining archaeids, with Lacunauchenius being sister to Mecysmaucheniidae ( $\mathrm{pp}=0.65)$, and with Patarchaea falling within Palpimanoidea $(\mathrm{pp}=1.0)$. The total evidence analysis recovered a monophyletic stem-group fossil archaeid clade $(\mathrm{pp}=0.89)$ consisting of the following species: Archaea paradoxa, Baltarchaea conica (C. L. Koch \& Berendt, 1854), Burmesarchaea grimaldii (Penney, 2003), Myrmecarchaea sp., Saxonarchaea dentata and Saxonarchaea diabolica. Posterior probability values were low for relationships within the stemgroup clade, likely reflecting a paucity of defining synapomorphies.

Mean divergence values indicate that Archaeidae (excluding Lacunauchenius and Patarchaea) originated in the JurassicTriassic $($ mean $=200 \mathrm{Ma}, 95 \% \mathrm{CI}=159-241$ ), with the Southern Hemisphere crown-group splitting off from the Northern Hemisphere stem-group in the Jurassic (mean $=173$ $\mathrm{Ma}, 95 \% \mathrm{CI}=136-211)$. The stem-group clade containing the Baltic, Bitterfeld and Burmese amber species began to diversify during the Cretaceous $($ mean $=134 \mathrm{Ma}, 95 \% \mathrm{CI}=$ 95-178). 


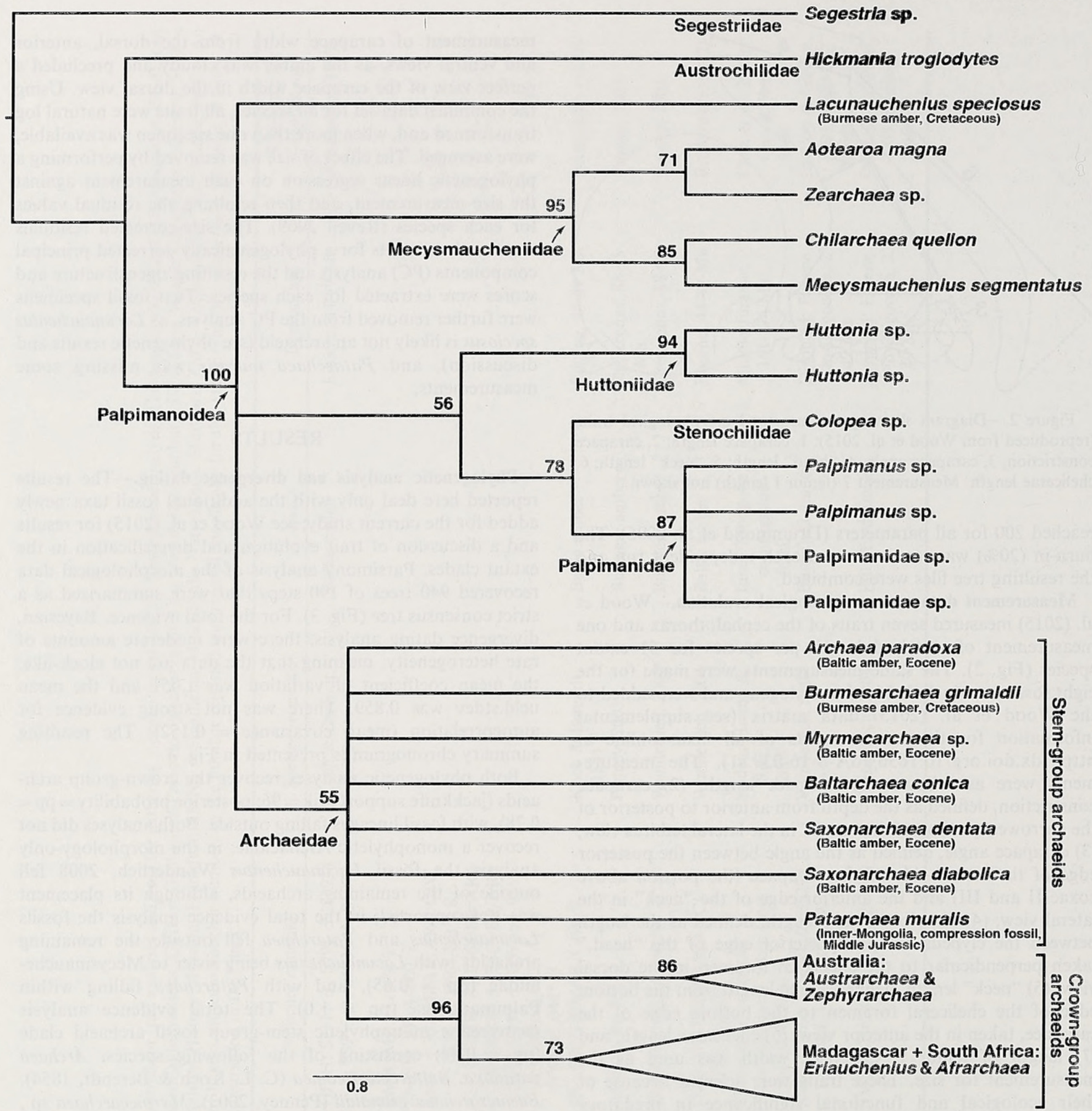

Figure 3.- Strict consensus tree summarizing 940 most parsimonious trees of 190 steps, obtained using TNT v.1.5, based on 111 morphological characters, with an outgroup of Segestria sp. The Australian and the Madagascar + South Africa clades are each a polytomy containing 7 species and 45 species, respectively. Node values represent jackknife support.

Morphological evolution.- The first three morphological PC axes had eigenvalues greater than one, and explained $52.3 \%$, $16.3 \%$, and $15.1 \%$ of the data (combined $83.7 \%$ ). PC1 showed variation between archaeid species with elongated features (chelicerae, carapace length and height ("necks"), legs and "heads"), with "necks" that are constricted, compared to species with shorter features and thicker "necks." PC2 described the variation between species with shorter heads and smaller carapace lengths, and with more constricted and more upright "necks," compared to species with elongated heads and longer carapace lengths, with "necks" that are more tilted and less constricted. PC 3 showed variation from one extreme of having shorter legs, shorter "heads," and more upright carapaces, to species with longer legs, longer "heads," and more tilted carapaces. Results are summarized in Table 2, and for PC1 and PC2, in Fig 5. 


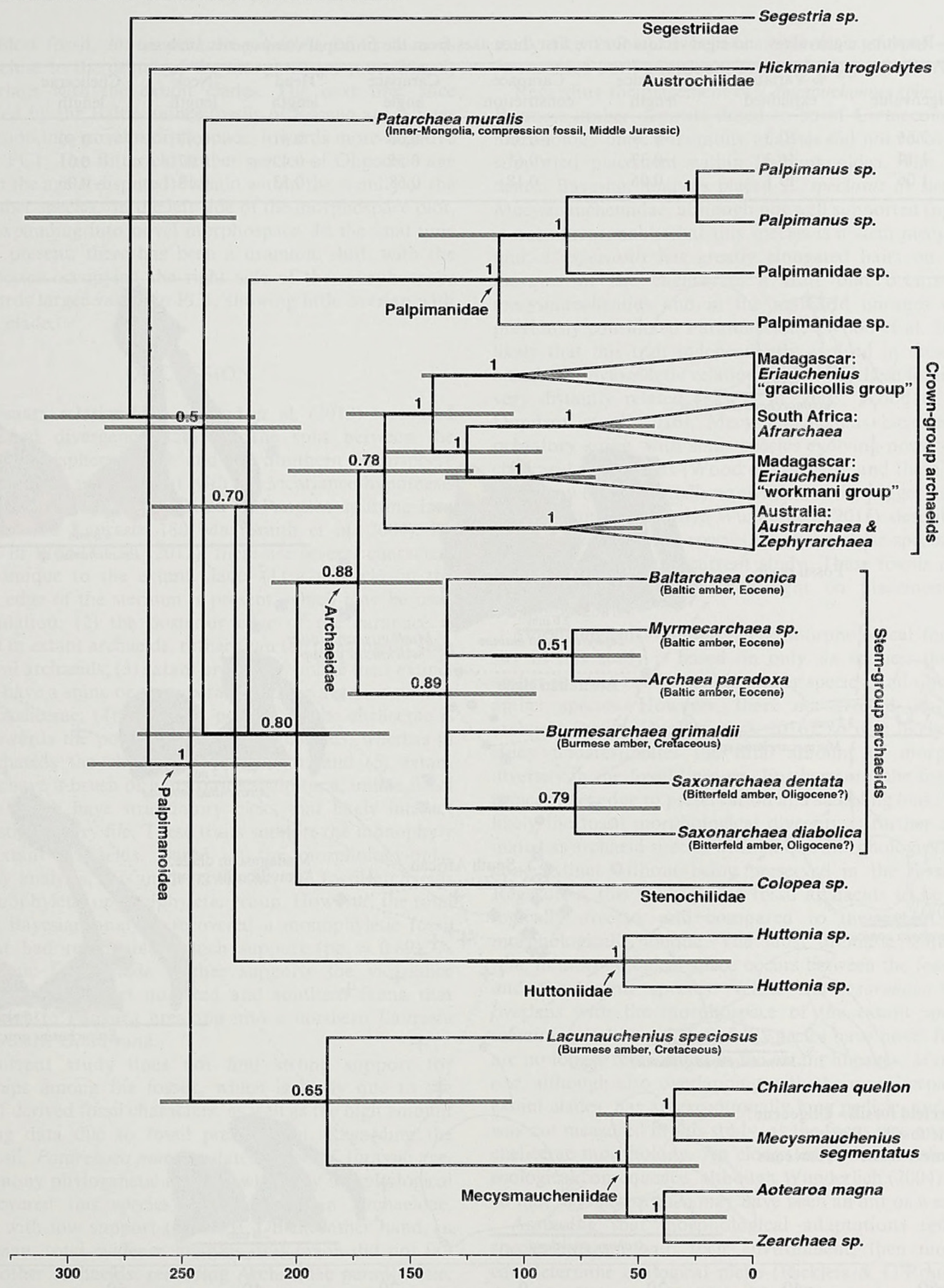

Figure 4.- Total evidence phylogeny from Bayesian analysis of the molecular and morphological data, with branch lengths drawn to refiect BEAST divergence age estimations. Error bars reflect the $95 \%$ Bayesian credible interval. Node values represent posterior probabilities, with branches with values less than 0.5 collapsed. Scale at bottom $=$ millions of years before present. 
Table 2.- Resulting eigenvalues and eigenvectors for the first three axes from the principal components analysis.

\begin{tabular}{lccccrrrrr}
\hline Trait & Eigenvalue & $\begin{array}{c}\text { \% Variation } \\
\text { explained }\end{array}$ & $\begin{array}{c}\text { Carapace } \\
\text { length }\end{array}$ & $\begin{array}{c}\text { Carapace } \\
\text { constriction }\end{array}$ & $\begin{array}{c}\text { Carapace } \\
\text { angle }\end{array}$ & $\begin{array}{r}\text { "Head" } \\
\text { length }\end{array}$ & $\begin{array}{r}\text { "Neck" } \\
\text { length }\end{array}$ & $\begin{array}{c}\text { Chelicerae } \\
\text { length }\end{array}$ & \multicolumn{1}{c}{$\begin{array}{c}\text { Femur I } \\
\text { length }\end{array}$} \\
\hline PC1 & 3.66 & 52.3 & 0.39 & -0.33 & 0.00 & 0.31 & 0.47 & 0.50 \\
PC2 & 1.14 & 16.3 & -0.37 & -0.61 & 0.55 & -0.42 & 0.07 & -0.01 \\
PC3 & 1.06 & 15.1 & 0.06 & 0.18 & 0.68 & 0.53 & 0.18 & -0.06 \\
\hline
\end{tabular}

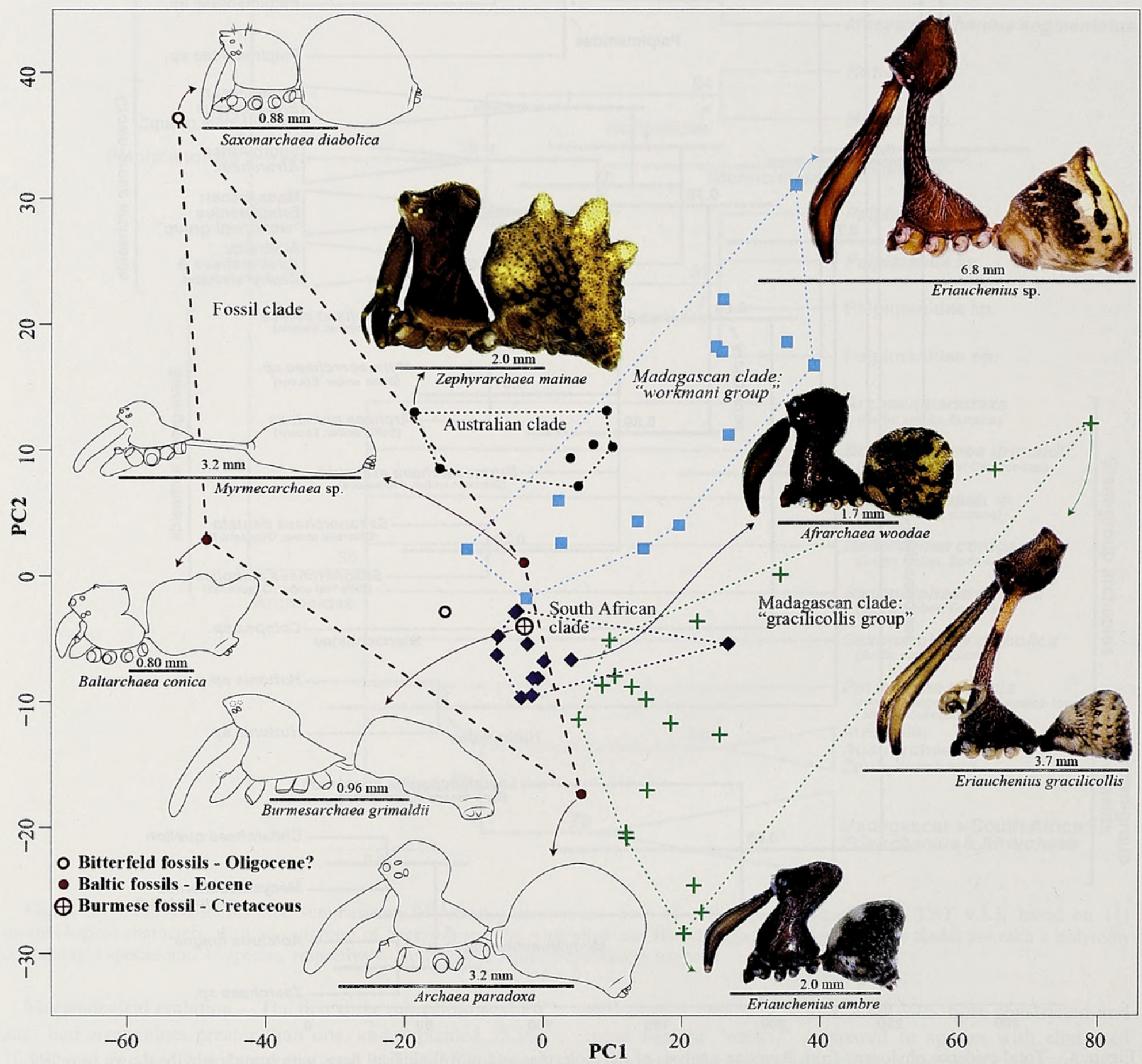

Figure 5.-Morphospace plot of the first two principal components for seven phylogenetically size-corrected traits (PC1 and PC2 explain $52.3 \%$ and $16.3 \%$ of the data), for 51 extant and 6 fossil species. A dashed line circumscribes the fossil clade and dotted lines circumscribe the four extant clades. Body shapes of 5 fossil and 5 living species are shown, lateral view, legs removed, not to scale, with the scale bar equaling the length of the first femur. Dashed lines marking some eyes in Burmesarchaea grimaldii are approximations. The following fossil specimens were excluded from the PC analysis and morphospace plot: Patarchaea muralis is missing some measurements due to fossil preservation; Lacunauchenius speciosus is likely not an archaeid. The image from the Australian clade, Zephyrarchaea mainae, is taken from Rix et al. (2011). 
The oldest fossil, Burmesarchaea grimaldii, of Cretaceous age, sits close to the center of the morphospace plot (Fig. 5) and overlaps with the extant clades. The next time slice represented by the Baltic amber fossils of Eocene age, shows an expansion into novel morphospace, towards more negative values in $\mathrm{PC1}$. The Bitterfeld amber species of Oligocene age (although the age is disputed) remain within the vicinity of the Baltic amber species, on the left side of the morphospace plot, yet still expanding into novel morphospace. In the final time slice, the present, there has been a dramatic shift, with the extant species occupying the right side of the morphospace plot towards larger values in $\mathrm{PCl}$, showing little overlap with the fossil clade.

\section{DISCUSSION}

Evolutionary relationships.-Wood et al. (2013) recovered an estimated divergence date for the split between the Northern Hemisphere fossils and the Southern Hemisphere extant clade that is consistent with the vicariance hypothesis that archaeid divergence is related to Pangaea splitting into Gondwana and Laurasia $180 \mathrm{Ma}$ (Smith et al. 2004). As discussed in Wood et al. (2012), there are several characters that are unique to the extant clade: (1) a tubercle on the posterior edge of the sternum is present, which may be used for stridulation; (2) the posterior edge of the carapace is truncated in extant archaeids, rather than the tapering off seen in the fossil archaeids; (3) extant archaeids, unlike their extinct relatives, have a spine or protuberance on the anterior surface of their chelicerae; (4) the distal portion of the chelicerae is curved towards the posterior in extant archaeids, whereas in fossil archaeids the chelicerae are straight; and (5) extant archaeids have a brush of hairs on the palp tarsi, unlike fossil archaeids which have stridulatory picks that likely interact with the stridulatory file. These traits support the monophyly of the extant archaeids. Based on the morphology-only, parsimony analysis, it is unclear whether the fossil archaeids are a monophyletic or paraphyletic group. However, the total evidence, Bayesian analysis recovered a monophyletic fossil clade that had reasonable branch support $(\mathrm{pp}=0.89)$. A monophyletic fossil clade further supports the vicariance hypothesis of a distinct northern and southern fauna that diverged due to Pangaea breaking into a northern Laurasia and a southern Gondwana.

The current study does not find strong support for relationships among the fossils, which is likely due to the paucity of derived fossil characters, as well as the high amount of missing data due to fossil preservation. Regarding the oldest fossil, Patarchaea muralis, dated to be of Jurassic age, the parsimony phylogenetic analysis with only morphological data recovered this species as falling within Archaeidae, although with low support $(\mathrm{jk}=55)$. On the other hand, in the Bayesian, total evidence analysis, this taxon did not fall with the other archaeids, rendering Archaeidae paraphyletic. The lack of a well-supported placement of this taxon makes sense because this is a compression fossil with many missing characters. This differs from the findings of Wood et al. (2015), which recovered Patarchaea as monophyletic with the remaining archaeids. This discrepancy may be due to the different taxon sampling in each study, particularly the inclusion of the fossil Lacunauchenius speciosus in the present study (see below). I believe Patarchaea should remain in Archaeidae until additional evidence suggests otherwise.

Regarding the placement of Lacunauchenius speciosus, from Burmese amber deposits dated to be of Cretaceous age, the morphology-only, parsimony analysis did not recover a wellsupported placement within Palpimanoidea. The total evidence, Bayesian analysis placed $L$. speciosus as sister to the Mecysmaucheniidae, although not well supported $(p p=65)$. It is not unreasonable that this species is a stem mecysmaucheniid: $L$. speciosus has greatly elongated hairs on the inner margins of the chelicerae, a trait that occurs only in mecysmaucheniids and in the malkarid lineages that were previously considered Pararchaeidae (Wood et al. 2012). It is likely that this trait independently evolved in these families based on phylogenetic relationships, with these families being very distantly related ( $\mathrm{Rix}$ et al. 2008; Wood et al. 2012; Dimitrov et al. 2016). Mecysmaucheniids have a trap-jaw predatory strike, with some species evolving power-amplified cheliceral movements (Wood et al. 2016), and these cheliceral hairs may be functionally equivalent to the trigger-hairs in the trap-jaw ants. Recently, Wunderlich (2015) described additional Lacunauchenius species, however, these specimens were not examined for the current study. These fossils as well as future discoveries may shed light on placement of this enigmatic genus.

Morphological evolution.- The morphological fossil diversity in this study is based on only six species: three Baltic amber species, two Bitterfeld amber species, and one Burmese amber species. However, there are around 20 described archaeid fossils (Dunlop et al. 2016), so it is likely that this study underestimates the total amount of morphological diversity in the fossil lineages. Furthermore, the fossil record is incomplete due to preservation and sampling bias. Thus, it is likely the fossil morphological diversity is further underestimated as archaeid species with unique morphologies may have gone extinct without being preserved in the fossil record. Regardless, this study found fossil archaeids to be morphologically diverse, and compared to the extant lineages, morphologically unique. The most dramatic shift through time in morphological space occurs between the fossil species and the extant species. While Burmesarchaea grimaldii overlaps with the morphospace of the extant species, the remaining Baltic and Bitterfeld species have novel forms that are no longer represented in the extant lineages. Myrmecarch$a e a$, although also overlapping with the morphospace of the extant clades, has an exceptionally long pedicle, and this trait was not measured in this study, as the focus was on carapace/ chelicerae morphology. An elongated pedicle is of unknown ecological consequence, although Wunderlich (2004) speculated that Myrmecarchaea may have been an ant or wasp mimic.

Assuming that morphological adaptations reflect how species interact with their environment, then morphology can determine ecological niche (Ricklefs \& O'Rourke 1975; Arnold 1983; Losos 1990). Thus, the high morphological diversity in fossil archaeids suggests that these extinct species occupied a diversity of niches. The fossil species occupy a different portion of the morphospace plot compared to the extant species (Fig. 5). This difference centers on $\mathrm{PC1}$, which relates to species having, at one extreme, short "necks," legs and chelicerae, and at the other extreme, species having 
elongated features. Comparing fossils of the past with extant species of the present, there has been a dramatic shift towards more elongated features. In extant archaeids previous research showed a correlation with body shape and habitat: species with long "necks," chelicerae, and legs occur more often in the vegetation, while species with shorter, more robust "necks," legs and chelicerae are found more often on the ground (Wood et al. 2015). I speculate that different forms occur in different habitats because there may be a different composition of spider fauna in the vegetation compared to on the ground, necessitating longer features in archaeids in order to exploit this prey; alternatively, life in dense leaf litter may constrain morphologies to be compact, whereas in the open vegetation this constraint may be lifted (Wood et al. 2015). Assuming similar evolutionary processes were at play in the past, this suggests that the more compact fossil species, such as Baltarchaea conica, Saxonarchaea dentata and S. diabolica, may have occurred in greater frequency on the ground. Although Myrmecarchaea sp. has a short "neck," this species has very long legs and an elongated pedicle, so it is difficult to infer the past habitat. Given the unique morphologies of the fossil species, it is also likely that in the past archaeids may have also occupied niches that are no longer occupied by extant species.

The archaeid distribution was more cosmopolitan in the past, spanning an array of sites over a vast amount of time. The first fossil record is from the Jurassic of Inner-Mongolia (assuming Patarchaea is an archaeid). Archaeids are then documented from the Cretaceous in Burmese amber, from the Eocene in Baltic amber, from the Oliogocene (although the date is disputed) in Bitterfeld amber, and finally, to the present day, occurring only in Australia, Madagascar, and South Africa. This extensive recorded history is quite remarkable given the incomplete nature of the fossil record. Archaeids have persisted for a duration of 165 million years, relatively unchanged considering the vast amount of time that has passed, and have gone extinct in different parts of the world. The most recent extinction is perhaps the most enigmatic: if Bitterfeld amber is assumed to be of Oligocene age, it was only around 25 million years ago that archaeids occurred in the northern parts of Europe. Although the age of Bitterfeld amber is presently disputed, it is likely younger than the Baltic amber of Eocene age, although some researchers suggest that the two deposits could be contemporaneous (Dunlop 2010). The paleoclimate of the Bitterfeld amber forests was likely warm and temperate (Dunlop 2010, and references therein), with overlap in species composition with the Baltic amber forests (Röschmann 1997; Mitov et al. 2015). While the Eocene was a very warm period in Earth's history, with tropical organisms occurring worldwide (Grimaldi \& Engel 2005), the Oligocene marked the beginning of a transition to a cooler, more variable climate due to Antarctic glaciation (Ivany et al. 2000; Zachos et al. 2001). Archaeid extinction from northern Europe may have been caused by this climatic transition, similar to what has been found for many other organisms that did not survive the Eocene-Oligocene boundary (Prothero 1994). Presently, the climates in the areas of the world where archaeids occur tend to be warmer, mesic yearround, and more stable (aseasonal) (Fjeldså \& Lovett 1997; Jury 2003; Rix \& Harvey 2012b). Through the integration of fossil and extant archaeid species our picture of their morphological evolution is more complete: there was a major shift in morphological space from the Oligocene to the present, with unique forms distinct to the Northern and Southern Hemispheres, and with the northern lineages going extinct while the southern lineages persisted.

\section{ACKNOWLEDGMENTS}

Funding for this project came from following National Science Foundation grants: DDIG 0909800; Postdoctoral Fellowship 1202873. Access to and loan of fossil specimens was made possible by Peter Jäeger at the Senckenberg Research Institute, Christian Neumann and Jason Dunlop at the Musuem für Naturkunde, Ulrich Kotthoff and Wolfgang Weitschat at the Geologisch-Paläontologisches Institut, Nikolaj Scharff at the Natural History Museum of Denmark, Günter Bechly at the Staatliches Museum für Naturkunde Stuttgart, David Grimaldi at the American Museum of Natural History and Joerg Wunderlich (private collection).

\section{LITERATURE CITED}

Arnold, S.J. 1983. Morphology, performance and fitness. American Zoologist 23:347-361.

Cambridge, O.-P. 1881. On some new genera and species of Araneidea. Proceedings of the Zoological Society of London 1881:765-775.

Carlson, R.L., P.C. Wainwright \& T.J. Near. 2009. Relationship between species co-occurrence and rate of morphological change in Percina darters (Percidae: Etheostomatinae). Evolution 63:767778.

Dimitrov, D., L.R. Benavides, M.A. Arnedo, G. Giribet, C.E. Griswold, N. Scharff et al. 2016. Rounding up the usual suspects: a standard target-gene approach for resolving the interfamilial phylogenetic relationships of ecribellate orb-weaving spiders with a new family-rank classification (Araneae, Araneoidea). Cladistics in press, DOI: $10.1111 /$ cla.12165.

Drummond, A.J., S.Y.W. Ho, M.J. Phillips \& A. Rambaut. 2006. Relaxed phylogenetics and dating with confidence. PLoS Biology 4:e88.

Drummond, A.J., M.A., Suchard, D. Xie \& A. Rambaut. 2012. Bayesian phylogenetics with BEAUti and the BEAST 1.7 Molecular Biology and Evolution 29:1969-1973.

Dunlop, J. 2010. Bitterfeld amber. Pp. 57-68. In Biodiversity of Fossils in Amber from the Major World Deposits. (D. Penney, ed.). Siri Scientific Press, Manchester, UK.

Dunlop, J.A., D. Penney \& D. Jekel. 2016. A summary list of fossil spiders and their relatives. World Spider Catalog, version 16.5. Accessed 1 June 2016. Natural History Museum, Bern. Online at http://wsc.nmbe.ch

Eskov, K.Y. 1992. Archaeid spiders from Eocene Baltic amber (Chelicerata, Araneida, Archaeidae) with remarks on the so-called "Gondwanan" ranges of Recent taxa. Neues Jahrbuch für Geologie und Paläontologie, Abhandlungen 185:311-328.

Eskov, K.Y. \& J. Wunderlich. 1995. On the spiders from Taimyr ambers, Siberia, with the description of a new family and with general notes on the spiders from the Cretaceous resins. Beiträge zur Araneologie 4:95-107.

Fjeldså, J. \& J.C. Lovett. 1997. Geographical patterns of old and young species in African forest biota: the significance of specific montane areas as evolutionary centres. Biodiversity \& Conservation 6:325-346.

Forster, R.R. \& N.I. Platnick. 1984. A review of the archaeid spiders and their relatives, with notes on the limits of the superfamily 
Palpimanoidea (Arachnida, Araneae). Bulletin of the American Museum of Natural History 178:1-106.

Goloboff, P.A., J.S. Farris \& K.C. Nixon. 2008. TNT, a free program for phylogenetic analysis. Cladistics 24:774-786.

Grimaldi, D. \& M.S. Engel. 2005. Evolution of the Insects. Cambridge University Press, New York.

Ivany, L.C., W.P. Patterson \& K.C. Lohmann. 2000. Cooler winters as a possible cause of mass extinctions at the Eocene/Oligocene boundary. Nature 407:887-890.

Jury, M.R. 2003. The climate of Madagascar. Pp. 75-87. In The Natural History of Madagascar. (S. Goodman, J. Benstead, eds.). University of Chicago Press, Chicago.

Koch, C.L. \& G.C. Berendt. 1854. Die im Bernstein befindlichen Crustaceen, Myriapoden, Arachniden und Apteren der Vorwelt. Pp. 1-124. In Die im Bernstein befindlichen organischen Reste der Vorwelt gesammelt in verbindung mit mehreren bearbeitetet und herausgegeben. (G.C. Berendt, ed.). In Commission der Nicolaischen Buchhandlung, Berlin.

Lewis, P.O. 2001. A likelihood approach to estimating phylogeny from discrete morphological character data. Systematic Biology 50:913-925.

Losos, J.B. 1990. The evolution of form and function: morphology and locomotor performance in West Indian Anolis lizards. Evolution 44:1189-1203.

Mitov, P., J. Dunlop \& D. Penney. 2015. A new species of Lacinius in amber (Arachnida: Opiliones). Fossil Record: Museum für Naturkunde Berlin 18:37-42.

Penney, D. 2003. Afrarchaea grimaldii, a new species of Archaeidae (Araneae) in Cretaceous Burmese amber. Journal of Arachnology 31:122-130.

Petrunkevitch, A. 1942. A study of amber spiders. Transactions of the Connecticut Academy of Arts and Sciences 34:119-464.

Prothero, D.R. 1994. The late Eocene-Oligocene extinctions. Annual Review of Earth and Planetary Sciences 22:145-165.

Pyron, R.A. 2011. Divergence time estimation using fossils as terminal taxa and the origins of Lissamphibia. Systematic Biology 60:466-481.

Rambaut, A., M.A. Suchard \& A.J. Drummond. 2014. Tracer v1.6. Online at http://tree.bio.ed.ac.uk/software/tracer/

Revell, L.J. 2009. Size-correction and principal components for interspecific comparative studies. Evolution 63:3258-3268.

Ricklefs, R.E. \& K. O'Rourke. 1975. Aspect diversity in moths: a temperate-tropical comparison. Evolution 29:313-324.

Rix, M.G. \& M.S. Harvey. 2012a. Australian Assassins, Part II: A review of the new assassin spider genus Zephyrarchaea (Araneae, Archaeidae) from southern Australia. Zookeys 191:1-62.

Rix, M.G. \& M.S. Harvey. 2012b. Phylogeny and historical biogeography of ancient assassin spiders (Araneae: Archaeidae) in the Australian mesic zone: evidence for Miocene speciation within Tertiary refugia. Molecular Phylogenetics \& Evolution 62:375-396.

Rix, M.G., M.S. Harvey \& J.D. Roberts. 2008. Molecular phylogenetics of the spider family Micropholcommatidae (Arachnida: Araneae) using nuclear rRNA genes (18S and 28S). Molecular Phylogenetics \& Evolution 46:1031-1048.

Röschmann, F. 1997. Ökofaunistischer Vergleich von Nematoceren-
Faunen (Insecta; Diptera: Sciaridae und Ceratopogonidae) des Baltischen und Sächsischen Bernsteins (Tertiär, Oligozän-Miozän). Paläontologische Zeitschrift 71:79-87.

Selden, P.A., J.M. Anderson, H.M. Anderson \& N.C Fraser. 1999. Fossil araneomorph spiders from the Triassic of South Africa and Virginia. Journal of Arachnology 27:401-414.

Selden, P.A., D.Y. Huang \& D. Ren. 2008. Palpimanoid spiders from the Jurassic of China. Journal of Arachnology 36:306-321.

Slater, G.J., L.J. Harmon \& M.E. Alfaro. 2012. Integrating fossils with molecular phylogenies improves inference of trait evolution. Evolution 66:3931-3944.

Smith, A.G., D.G. Smith \& B.M. Funnell. 2004. Atlas of Mesozoic and Cenozoic coastlines. Cambridge University Press, Cambridge.

Wood, H. 2008. A revision of the assassin spiders of the Eriauchenius gracilicollis group, a clade of spiders endemic to Madagascar (Araneae : Archaeidae). Zoological Journal of the Linnean Society 152:255-296.

Wood, H.M., R.G. Gillespie, C.E. Griswold \& P.C. Wainwright. 2015. Why is Madagascar special? The extraordinarily slow evolution of pelican spiders (Araneae, Archaeidae). Evolution 69:462-481.

Wood, H.M., C.E. Griswold \& R.G. Gillespie. 2012. Phylogenetic placement of pelican spiders (Archaeidae, Araneae), with insight into evolution of the "neck" and predatory behaviours of the superfamily Palpimanoidea. Cladistics 28:598-626.

Wood, H.M., C.E. Griswold \& G.S. Spicer. 2007. Phylogenetic relationships within an endemic group of Malagasy 'assassin spiders' (Araneae, Archaeidae): ancestral character reconstruction, convergent evolution and biogeography. Molecular Phylogenetics \& Evolution 45:612-619.

Wood, H.M., N.J. Matzke, R.G. Gillespie \& C.E. Griswold. 2013. Treating fossils as terminal taxa in divergence time estimation reveals ancient vicariance patterns in the palpimanoid spiders. Systematic Biology 62:264-284.

Wood, H.M., D.Y. Parkinson, C.E. Griswold, R.G. Gillespie \& D.O. Elias. 2016. Extremely rapid predatory strikes evolved repeatedly in trap-jaw spiders. Current Biology 26:1-5.

Wunderlich, J. 2004. Fossil and extant spiders (Araneae) of the superfamily Eresoidea s.l., with special reference to the Archaeidae and remarks on some higher taxa of the superfamily Araneoidea. Beiträge zur Araneologie 3:747-808.

Wunderlich, J. 2008. The dominance of ancient spider families of the Araneae: Haplogyne in the Cretaceous, and the late diversification of advanced ecribellate spiders of the Entelegynae after the Cretaceous-Tertiary boundary extinction events, with descriptions of new families. Beiträge zur Araneologie 5:524-675.

Wunderlich, J. 2015. On the evolution and the classification of spiders, the Mesozoic spider faunas, and descriptions of new Cretaceous taxa mainly in amber fro Myanmar (Burma). Beiträge zur Araneologie 9:21-408.

Zachos, J., M. Pagani, L. Sloan, E. Thomas \& K. Billups. 2001. Trends, rhythms, and aberrations in global climate $65 \mathrm{Ma}$ to present. Science 292:686-693.

Manuscript received 14 June 2016, revised 27 September 2016. 


\section{$2 \mathrm{BHL}$ Biodiversity Heritage Library}

Wood, Hannah M. 2017. "Integrating fossil and extant lineages: an examination of morphological space through time (Araneae: Archaeidae)." The Journal of arachnology 45(1), 20-29. https://doi.org/10.1636/joa-s-16-039.1.

View This Item Online: https://www.biodiversitylibrary.org/item/274714

DOI: https://doi.org/10.1636/joa-s-16-039.1

Permalink: https://www.biodiversitylibrary.org/partpdf/289889

\section{Holding Institution}

Smithsonian Libraries

\section{Sponsored by}

Biodiversity Heritage Library

\section{Copyright \& Reuse}

Copyright Status: In Copyright. Digitized with the permission of the rights holder

Rights Holder: American Arachnological Society

License: https://creativecommons.org/licenses/by-nc-sa/4.0/

Rights: http://www.biodiversitylibrary.org/permissions/

This document was created from content at the Biodiversity Heritage Library, the world's largest open access digital library for biodiversity literature and archives. Visit BHL at https://www.biodiversitylibrary.org. 